\title{
A MODERNIDADE ALIMENTAR: ENTRE A SUPERABUNDÂNCIA E A INSEGURANÇA*
}

\author{
Modernity Food: Between Insecurity \\ and Overconsumption \\ Jesús Contreras**
}

\begin{abstract}
RESUMO
Depois de séculos de má nutrição, decorrente da falta de alimentos no mundo, hoje, nas sociedades industrializadas dos comensais contemporâneos, a preocupação dominante é saber o que comer e em que proporções. A realidade se confronta com a situação de saúde, com o estado nutricional da sociedade, com a abundância e com o bem-estar e, também, com a má nutrição gerada pela abundância. O termo segurança alimentar adquiriu significados diferenciados. Os sistemas alimentares passaram de ecossistemas diversificados a outros hiperespecializados e integrados em vastos sistemas de produção alimentar, em escala internacional. A produção mundial de alimentos ao mesmo tempo em que desapareceram numerosas variedades vegetais e animais que por muito constituíram a base das dietas. Com o aumento na produção e no consumo de alimentos industrializados, houve uma ampliação do repertório alimentar, homogeneizando o mesmo, sem que se possa avaliar as consequências do consumo sobre a saúde dos indivíduos. Há uma artificialização da alimentação e sua ingestão se supõe cheia de riscos, gerando no consumidor uma considerável incerteza, desconfiança e ansiedade.
\end{abstract}

Palavras-chave: modernidade alimentar; globalização; repertório alimentar; segurança alimentar.

\footnotetext{
ABSTRACT

After centuries of malnutrition, decurrent food shortages in the world, today, in industrialized societies, diners' contemporaries, the dominant

* Tradução: Regina Amelia Darriba Rodríguez - DELEM-UFPR.

** Observatorio de Alimentación - Universidad de Barcelona. E-mail: contreras@ub.edu
} 
concern is what to eat and in what proportions. The reality is confronted with the situation of health, with nutritional status in society, the abundance and well-being and also with malnutrition caused by the abundance. The term food security has acquired different meanings. Food systems have diversified to other ecosystems, and integrated hyper specialized extensive systems of food production on an international scale. The world food production increased, while missing numerous plant and animal varieties that constituted the basis for much of diets. With the increase in production and consumption of foods an expansion of food repertoire was caused. As consequences of this we point the homogenization of food and lack of assess of the impact of consumption on the individuals' health. There is an artificiality of food and its ingestion is assumed full of risks, resulting in a considerable consumer uncertainty, mistrust and anxiety.

Key-words: food modernity; globalization; food repertoire; food security.

\section{A modernidade alimentar}

Depois de séculos de má nutrição recorrente, como consequência de uma determinada falta de alimentos, hoje, nas sociedades industrializadas, é possível afirmar, salvo exceções, que o mundo inteiro come e que se instalou um sentimento de afluência e inclusive de superabundância alimentar. Tradicionalmente, até a década de 1950, inclusive 1960, para as classes trabalhadoras, uma boa alimentação era, acima de tudo, uma alimentação "nutritiva", isto é, "sã", porém principalmente abundante e saciável. Hoje, ao contrário, a maior parte da população pensa que "comemos exageradamente". O "temor de que a comida não seja suficiente" retrocedeu. Hoje, a preocupação dominante é cada vez mais de caráter qualitativo. Desde os anos 1980, o termo mais utilizado tanto pelas mães de família como pelos dietistas para caracterizar uma boa alimentação é o de equilibrio. Atualmente, de acordo com Fischler (1995), no espírito dos comensais contemporâneos, a questão crucial é cada vez mais saber o que comer e em que proporção. A preocupação quantitativa não está ausente, porém se apresenta como termo de restrição. As pesquisas mostram, efetivamente, que entre um quarto e um quinto da população mundial está fazendo algum tipo de regime. 
Por outro lado, ao longo da história dos países chamados desenvolvidos, em nenhum outro momento os seres humanos se encontram tão saudáveis e durante tanto tempo como na atualidade. De fato, todos os dados apontam na mesma direção: nunca na história das sociedades ocidentais a população teve tanto o que comer e esteve tão livre da fome ou da escassez como agora e nunca antes havia alcançado uma expectativa de vida tão alta. Efetivamente, ao longo do século XX, na Espanha, a expectativa de vida ao nascer mais do que duplicou, passando de 34,7 anos em 1900 a 77,5 no ano 2000. Contudo, se essa realidade se confronta com a situação da saúde e com o estado nutricional da sociedade, principalmente, com a opinião que se percebe, chega-se a imagens totalmente diferentes. Aparentemente, ao menos, as mudanças produzidas nos regimes alimentares da maior parte dos países destacam, no lugar da abundância e do bem-estar, certa má nutrição. Nas sociedades industrializadas, uma vez que se resolveu o problema de garantir o nível de subsistência, o interesse se centraliza em saber se a sua alimentação, escolhida mais ou menos livremente e entre numerosas opções, acaba por ser confiável em termos de qualidade e de inocuidade. Efetivamente, até metade do século XX, quando se falava de segurança alimentar era para referir-se ao abastecimento. Nos últimos anos, indiscutivelmente, o termo "segurança alimentar" adquiriu outro significado. Nos países mais industrializados, se compreende como o consumo de alimentos livres de riscos para a saúde. Esta segunda acepção se explica, talvez, pelo fato de que, cada vez mais, as sociedades tomam precauções para minimizar os possíveis perigos associados aos alimentos, tais como a intoxicação ou a contaminação. Para isso, recomendam-se medidas preventivas, pesquisa-se e aplicam-se técnicas de manipulação específica, de conservação etc.

Como não se tinha tanto conhecimento, como hoje, sobre os alimentos, sobre as doenças e sobre a biologia e a fisiologia humana, os avanços científicos e tecnológicos desenvolvidos ao longo das últimas décadas permitem alguns tipos de análises extraordinariamente pormenorizadas, de tal maneira que de qualquer "alimento" ou produto se pode conhecer sua composição qualitativa e quantitativa até o mínimo detalhe. Assim, resulta significativo que uma campanha realizada pelo Ministério Sanitário espanhol tivesse como slogan a seguinte afirmação: "Lendo as etiquetas se come melhor". Desse modo, e a julgar pelas publicações científicas, pela sua repercussão nos meios de comunicação e, inclusive, pela publicidade 
alimentar, a nossa sociedade contemporânea não parece que "come" maçãs, carne de frango ou de porco, atum, couve-flor, pão, iogurte ou bebe vinho ou cerveja, e, sim, parece que consome cálcio, ferro, polifenóis, flavonoides, vitaminas das mais diversas, carotenoides, glucosinolatos, fibra, ácidos graxos, licopeno, esteróis, ácido oleico, fósforo, álcool etílico etc. As categorias relativas aos alimentos parecem ter se modificado consideravelmente no sentido de uma maior "cientificização". Ao mesmo tempo em que conhecemos melhor a composição dos produtos alimentares, também conhecemos cada vez mais e melhor os efeitos dos diferentes nutrientes ou substâncias sobre nosso organismo. Consequentemente, com tudo isso, hoje, os cientistas, os responsáveis pelo sanitarismo público e as indústrias agroalimentares nos recomendam com mais precisão e com mais convencimento o que devemos ingerir para estar sãos e para prevenir as mais diferentes doenças.

Definitivamente, pode-se pensar, então, que nunca se havia comido tanto como agora, de maneira tão variada e melhor. Nunca estivemos tão saciados como agora. Nunca tínhamos vivido tanto, de maneira tão variada e melhor que agora. Nunca tivemos tantos controles alimentares, tecnologias tão eficientes e sofisticadas para garantir a segurança (inocuidade) de nossos alimentos, as autoridades, os cientistas, os meios de comunicação e as organizações de consumidores tão preocupados com o nosso bem-estar como hoje. Isto é, nunca existiu tanta segurança alimentar. No entanto, a "insegurança" não desaparece e, inclusive, aumentam as incertezas e as dúvidas sobre o que comemos e os possíveis $\operatorname{riscos}^{1}$ que podem implicar na nossa comida, isto é, os danos potenciais/prováveis para a nossa saúde. Isto é, nunca estivemos tão preocupados com a nossa saúde e a nossa alimentação como neste momento. De acordo com o CREDOC (2002), se em 1997 35\% dos franceses opinavam que os produtos alimentares apresentavam alguns riscos para a saúde e $20 \%$ diziam que apresentavam riscos importantes, três anos depois, em 2000, estes valores haviam se tornado mais negativos, aumentando para $40 \%$ e $30 \%$, respectivamente. Parece ser, então, que, cada vez, uma maior quantidade da população tem mais dúvidas sobre a

1 As percepções e representações do risco com relação aos alimentos foram objeto de numerosos estudos (STEEMKAMP, 1990; POULSEN; JUHL; KRISTENSEN; BECH; ENGELUND, 1996; GRUNERT; LARSEN; MADSEN; BAADSAGAARD, 1996), proporcionando bases úteis para analisar as crises alimentares e o grau de confiança dos consumidores na segurança dos alimentos e na eficácia dos controles. 
inocuidade alimentar. Por quê? A resposta é complexa e exige analisar o processo de transformações ocorridas em todas e em cada uma das fases da cadeia alimentar, assim como nas atitudes, representações e percepções sociais relativas aos alimentos.

\section{A globalização dos repertórios alimentares}

Como destacou Fischler (1995), os sistemas alimentares passaram, em pouco tempo, de alguns ecossistemas muito diversificados a outros hiperespecializados e integrados em vastos sistemas de produção agroalimentar em escala internacional. Deste modo, aumentou consideravelmente a produção mundial de alimentos, ao mesmo tempo em que desapareceram numerosas variedades vegetais e animais que haviam constituído a base de dietas de âmbitos mais ou menos localizados. Mesmo assim, paralelamente a este processo, as tarefas da cozinha doméstica foram transferidas em grande medida para a indústria. Como consequência de tudo isso, cada vez se consome uma maior quantidade de alimentos processados industrialmente. Este fenômeno não acontece somente nos países mais industrializados e, apesar das reduções, matizes, graus e diferentes consequências, acabam ocorrendo em todos os países do mundo. Tudo isso supõe uma ampliação do repertório alimentar, ao mesmo tempo em que ocorre uma homogeneização do mesmo. Hoje, em qualquer país do mundo, o essencial da sua alimentação provém de um sistema de produção e de distribuição cuja escala é planetária.

Os comportamentos alimentares nos países industrializados estão, hoje, mais baseados nas estratégias de marketing das empresas agroalimentares que na experiência racional ou nas práticas tradicionais (ABRAHAMSSON, 1979). Esta estratégia tem uma dimensão "multinacional" e/ou "global" e afeta também os países do Terceiro Mundo, onde os maiores ou menores efeitos dependem da medida em que as diferentes comunidades se incorporam a uma economia monetária e as mudanças que se introduzem nos modos de produção supõem uma menor dedicação à terra, ao trabalho e à produção de subsistência e maior aos cultivos comerciais (MANDERSON, 1988, p. 179). 
As grandes empresas agroalimentares controlam cada vez mais os processos de produção e distribuição de alimentos. Certos alimentos, por outra parte, são produzidos cada vez mais "industrialmente" e isso apesar de que a própria noção de "indústria alimentar" (Cf.: ATKINSON, 1983, p. 10-16; FISCHLER, 1979, p. 201) resulta repugnante para muita gente. Efetivamente, o consumo de alimentos processados vem aumentado consideravelmente nos últimos trinta anos e continua, apesar dos seus detratores morais, gastronômicos, econômicos e dietéticos, tanto nos países mais industrializados como nos do Terceiro Mundo. Aumenta o consumo desses produtos em quantidade de unidades, em diversidade de produtos e em porcentagem do orçamento familiar. O processo está longe de ver seu ponto final porque a tecnologia alimentar está desenhando constantemente novos produtos e as últimas aplicações alimentares da biotecnologia anunciam numerosas novidades alimentares para um futuro mais ou menos imediato, tais como, por exemplo: tomates que não apodrecem; leite de vaca com vacinas incorporadas; beringelas brancas; arroz vermelho e aromatizado; batatas com um amido de melhor qualidade, que as fará mais crocantes quando fritas; milho com um leve sabor de manteiga etc.

Definitivamente, hoje em dia, os países industrializados podem dispor de uma maior variedade de alimentos ao longo do ano. É certo, também, que para que isso tenha sido possível foi necessário recorrer (para permitir a conservação e o transporte) a um uso generalizado e crescente de aditivos (conservantes, corantes, aromatizantes etc.). Esses aditivos contribuem, também, por uma parte, para uma homogeneização progressiva dos alimentos e, por outra, supõem uma ingestão sistemática e prolongada de substâncias cujas consequências não são ainda bem conhecidas.

A evolução dos modos de vida para atividades menos produtivas está na origem destes processos. O aumento do nível de vida, associado a um desenvolvimento do salário, assim como a uma evolução do lugar e do papel social das mulheres, comportou um transpasso da produção doméstica alimentar para o sistema de mercado. Tudo isso se traduziu em uma regressão do autoconsumo, em uma demanda crescente de produtos prontos para comer e em um aumento da frequência das diversas formas de restauração. Mesmo assim, a individualização crescente dos modos de vida comportou certa desritualização das adoções alimentares, reforçada pela diminuição das influências religiosas e morais. O convívio associado às 
refeições perdeu importância. Aumentou a diversidade dos tipos de adoções alimentares de acordo com os contextos (lugares, momentos, convívios...) e, como consequência, aumentou o leque de expectativas relativas às características qualitativas dos produtos alimentares (LAMBERT, 1997, p. 55).

\section{Rupturas nos sistemas de representação alimentar e desconfiança dos consumidores}

A "revolução industrial" aplicada à indústria alimentar permitiu nas últimas décadas incrementar consideravelmente a disponibilidade de todo tipo de alimentos até o ponto de, como dissemos, passar da escassez para a superabundância. Este é o aspecto positivo da dita revolução, porém há outros. Como destacou Fischler (1979, p. 198-200), em poucas décadas a revolução industrial, a especialização e os rendimentos crescentes da produção agrícola, o desenvolvimento hipertrófico das cidades... tudo isso contribuiu para criar uma "modernidade alimentar" que transtornou ou, inclusive, subverteu a relação do homem com sua alimentação. Com a evolução da produção e da distribuição agroalimentar, perdeu-se progressivamente todo o contato com o ciclo de produção dos alimentos: sua origem real, os procedimentos e as técnicas empregadas para sua produção, sua conservação, seu armazenamento e seu transporte. Os consumidores somente têm um conhecimento parcial desta evolução, que vai desde o que poderíamos chamar de situação "tradicional" ou "pré-industrial" até a atual era do cracking e o ensamblado. F. Gruhier (1989) chegou a dizer que os animais que hoje consumimos (também os vegetais) são autênticos mutantes que têm pouco a ver com seus "antepassados" de 30 ou 40 anos atrás, enquanto que o homem contemporâneo, biologicamente ao menos, se parece como duas gotas de água com o seu antepassado medieval. Neste quadro evolutivo, o rol das indústrias alimentares mudou e o alimento se apresenta de uma maneira dual. Por uma parte, se artificializa e, por outra, deve conservar um status "natural", pois este é o único nexo tangível com a natureza para o consumidor. Assim, pois, se com o tempo as práticas alimentares podem ser evolutivas, a mudança parece tropeçar na insatisfação 
do consumidor, confrontado, por exemplo, com os alimentos "industriais", que os encontra insípidos, com pouco sabor e, inclusive, perigosos.

Agora bem, enquanto que os alimentos tenham mudado muito durante esses últimos 40 anos, sua simbologia ou suas representações sociais se caracterizariam por uma maior duração ou continuidade. Efetivamente, os sistemas de representações dos consumidores estão evoluindo mais lentamente que os sistemas de produção-distribuição, com suas inovações tecnológicas relativas tanto aos produtos como à embalagem, aos lugares de produção como ao transporte, ao armazenamento e à distribuição. Tudo isso obriga a se perguntar pelo futuro das categorizações implícitas que condicionam os gostos e as recusas alimentares (MAHO; PINSON, 1989, p. 202). Por exemplo, desde um ponto de vista organoléptico, não somente os gastrônomos se interessam pela compatibilidade entre a tecnologia alimentar e a manutenção do próprio sabor de cada tipo de alimento.

Assim mesmo, com a chamada cozinha industrial, nem a composição nem a forma dos alimentos evocam um significado preciso e familiar; pelo contrário, podem evocar já qualquer coisa como, por exemplo, "iscas de carne" ou "palitos de caranguejo". Assim, o risco maior que parece projetar a modernidade alimentar refere-se à incapacidade dos consumidores modernos para classificar os produtos da indústria alimentar (ARIÈS, 1997). Entre a tecnologia, de um lado, e o marketing e a publicidade, do outro, as referências culturais da alimentação foram destruídas. O alimento se converteu em um objeto sem história conhecida e o consumidor moderno não sabe o que realmente está comendo (FISCHLER, 1979, p. 202).

Com a multiplicação das eleições gustativas alimentares, é necessário considerar que o consumidor, hoje, não é mais que um conhecedor parcial da variedade de gostos ou sabores dos alimentos cujas qualidades organolépticas e microbiológicas são melhoradas. O espaçamento entre a repetição de uma mesma experiência alimentar faz com que seja mais difícil a memorização dos sabores particulares e a constituição de uma memória gustativa pessoal. Assim mesmo, a possível confusão em relação às representações alimentares pode afetar as imagens sobre os sistemas de produção, assim como elementos sobre os lugares de aprovisionamento e os sistemas de distribuição.

Hoje, a artificialização da alimentação suscita problemas no consumidor. Provoca uma ruptura com as regras ancestrais, porém, também 
a oportunidade de fazer evoluir o perfil do comensal para um indivíduo consciente de seu passado cultural, autônomo (livre de suas escolhas alimentares em abundância de oferta), responsável (formado no conhecimento das características dos alimentos) e promotor de sua própria riqueza alimentar. Fischler (1990) mostra que a ausência de consenso implícito ou explícito unívoco sobre a arte e a maneira correta de se alimentar comporta para o comensal uma grande incerteza e uma verdadeira ansiedade. Ademais, o desconhecimento dos modos de fabricação dos alimentos e das matérias-primas utilizadas se acrescentam a esta confusão, desenvolvendo-se entre os consumidores uma atitude de desconfiança com relação à oferta alimentar mais pletórica que nunca. Resulta fundamental a familiarização na aceitação dos novos alimentos. Sylvander e Melet (1994) evocam "a incerteza sobre as definições dos produtos" e sobre "a qualidade dos produtos" que estariam na origem de "um aumento da desconfiança dos consumidores constatada desde os anos 1960, assim como do desenvolvimento de políticas de gestão de qualidade nas empresas. Do complexo sistema internacional de produção e distribuição alimentar, os consumidores somente conhecem os elementos terminais: os lugares de distribuição e os produtos. O resto é uma verdadeira caixa-preta, que implica em um medo tanto maior na medida em que a subsistência está associada à alimentação.

Os produtos alimentares disponíveis são identificados pelos indivíduos se suas características percebidas fisicamente por seus órgãos sensoriais têm um sentido, um significado, encontrado pelo cérebro no sistema de representações preestabelecido. Os consumidores resumem sua percepção por ideias sobre a autenticidade e a qualidade. Isso significa a perfeita adequação à sua cultura, ao seu sistema de representações. A menor separação desses produtos em relação a esta cultura pode lhe fazer perder seu sentido até o ponto em que não pareçam verdadeiros alimentos, que pareçam pastiches, artefatos, "plástico", que "não têm alma". Neste sentido, o desenhista F. Jegou (1991) precisa que "a indústria proporciona um fluxo de alimentos sem memória", no que a dimensão simbólica da alimentação já não é o resultado de um lento processo de sedimentação entre o homem e seu alimento, e sim é anterior. Assim, os "novos alimentos" podem ser classificados no limite do comestível e sua ingestão se supõe cheia de riscos. Assuntos muito destacados pelos meios de comunicação (a crise das "vacas loucas", por exemplo) reforçam claramente esta ansiedade 
latente. Os novos produtos possuem por sua essência elementos exteriores à cultura de quase a totalidade dos indivíduos aos quais são apresentados (LAMBERT, 1997, p. 57-58).

A cultura alimentar ainda hoje dominante não parece ter integrado o novo contexto de produção-distribuição caracterizado por uma agricultura muito mecanizada que proporciona as matérias-primas às indústrias que, por sua vez, procedem a transformações cada vez mais sofisticadas e vendem às grandes superfícies os produtos já empacotados. No universo de representações ainda hoje dominante, o universo do comestível está constituído por alimentos procedentes do setor primário, isto é, produtos brutos e frescos com uma imagem mental de natureza, em oposição a outros produtos procedentes do setor industrial - que formariam o universo do não comestível. A percepção atual dos produtos alimentares parece que continua se elaborando a partir deste duplo universo de representações, posto que a maioria das pessoas entrevistadas a respeito considera que "os produtos 'industriais' não são tão bons como os 'naturais"” (LAMBERT, 1996, p. 157-158).

Definitivamente, a chamada "artificialização" da alimentação e o desconhecimento a respeito dos modos de fabricação dos alimentos e das verdadeiras matérias-primas utilizadas na sua elaboração provocam no consumidor moderno uma considerável incerteza, desconfiança e ansiedade. Inclusive, a noção de "granja indústria" acaba sendo repugnante para muitas pessoas. Em certa medida, esta repugnância deriva de diferentes tipos de repulsão com relação aos tratamentos "desumanos" a que são submetidos os animais. Do mesmo modo, a agroindústria é vilipendiada ao ser vista como uma desperdiçadora dos recursos naturais e baseada no uso de fertilizantes químicos "artificiais" (ATKINSON, 1983, p. 16). Por tudo isso, não deve parecer estranho que os principais desafios ao que hoje se deve fazer frente à pesquisa na indústria agroalimentar sejam, precisamente, os de resolver os problemas que a própria indústria gerou nos consumidores e que podem se resumir na necessidade de restabelecer a confiança e a segurança na inocuidade sanitária de seus próprios produtos (seja no nível das consequências que sua ingestão possa ter no consumidor, seja nas consequências que sua produção possa ter no meio ambiente) e em sua qualidade organoléptica. 


\section{Um caso paradigmático: as "vacas loucas"}

Com a globalização, as intoxicações alimentares deixam de ser locais e passam a ser internacionais. Uma rede de intercâmbios em escala planetária e os sistemas de distribuição em massa que propõem ao consumidor empanturrado de enormes quantidades de mercadorias provocam que a indústria alimentar seja muito sensível aos pânicos. Efetivamente, nestes sistemas muito complexos, dos quais participam sem dominá-los, os consumidores desorientados escutam todos os rumores negativos de envenenamento, frequentemente lançados sem discernimento por uma imprensa sensacionalista que privilegia a manchete alarmante. Os pânicos alimentares se multiplicam, provocando reações frequentemente desordenadas por parte das autoridades. Minorias influentes manipulam os temores dos consumidores. Abundam os exemplos: o chamado "panfleto de Villejuif" sobre os riscos cancerígenos dos aditivos alimentares; ameaça de envenenamentos massivos e indiscriminados como forma de protesto político; ameaças de envenenamento de alimentos como chantagem econômica às empresas alimentares etc. Em qualquer caso, a complexidade crescente do sistema alimentar e mediático atual contribui para alimentar um número cada vez maior de pânicos alimentares que misturam o imaginário e o real (CAMPION-VINCENT, 1994, p. 89-92).

Nem sempre a informação proporcionada ao consumidor para prevenir e superar seus temores resulta suficiente e/ou adequada. Diz Lambert (1997) que algumas informações somente podem modificar a cultura dos indivíduos de um modo muito marginal porque, sobretudo, a desconfiança do consumidor é um estado afetivo primário ligado ao seu instinto de sobrevivência e não se modifica com um simples raciocínio. Ademais, os consumidores europeus não parecem admitir nenhum tipo de especulação com os riscos para sua saúde derivados do consumo de qualquer tipo de produto alimentício. No entanto, a imprensa diária informa regularmente os perigos derivados das aplicações industriais da pesquisa agroalimentar. Um exemplo recente extraído da imprensa espanhola:

O uso abusivo dos antibióticos no setor pecuarista projeta uma ameaça crescente à saúde dos consumidores, de acordo com o que advertiram oitenta especialistas reunidos na semana pas- 
sada em Berlim, na Organização Mundial da Saúde. O abuso de antibióticos [...] acelera a proliferação de cepas de bactérias resistentes aos antibióticos. Mesmo que a ingestão destas bactérias não costume ter consequências para a saúde, pode causar graves doenças - e às vezes inclusive a morte - em um pequeno número de consumidores. $\mathrm{O}$ fato de que as bactérias sejam resistentes aos antibióticos não faz senão dificultar o tratamento dos pacientes (CORBELLA, J. In: A Vanguardia, 22-10-1997, p. 25).

Este tipo de considerações em forma de notícias ou de artigos é muito frequente, como também é a imposição de multas por alimentação indevida dos animais destinados ao consumo humano de carne. Dentro de um contexto assim, estourou em 1996 a denominada crise das "vacas loucas", que gozou de um extraordinário seguimento por parte dos meios de comunicação de numerosos países e que foi reeditado, com acréscimo, em sua segunda edição, a do 2000-2001. Em boa medida, esta crise contribuiu para reforçar a desconfiança e a ansiedade dos consumidores com respeito aos produtos da carne. É possível dizer que a chamada crise das "vacas loucas" permitiu descobrir alguns aspectos da mencionada caixa- preta relativa à cadeia de produção da carne de gado. Uma cadeia muito fechada e na qual, praticamente, se aproveitava tudo. Para fabricar essas carnes, utilizam-se colunas vertebrais sobre as quais se extraem os resíduos da carne, de tal maneira que o processo de recuperação comporta, também, os outros tecidos que pode estar unidos, como o sistema nervoso central. Estas partes estavam destinadas a certas preparações à base de carne (ravioli, linguiças, hamburguer etc.). Os ingleses proibiram esta prática em dezembro de 1995. Previamente, em 1989, haviam proibido para o consumo humano certos despojos: o cérebro, a medula espinhal, o intestino, o baço etc. Por outra parte, não foram tanto as farinhas das carnes as que foram proibidas (em qualquer caso não se proibiu sua exportação), e sim as proteínas de ruminantes na alimentação de ruminantes. Assim se apresentava o problema da definição da carne, de tal maneira que esta palavra não cobre a mesma realidade para o consumidor que para os industriais (SAVEY, 1997).

As reações frente à "vaca louca" se inscrevem dentro das tendências de mudanças observadas depois dos anos 1980. As estatísticas de consumo de carnes posteriores à crise das "vacas loucas" mostraram uma diminuição 
no consumo de carnes bovinas, ainda que compensado parcialmente pelo consumo de outras carnes e de peixes. Assim mesmo, desenvolveram-se comportamentos completamente vegetarianos. Essas mudanças de comportamento encontraram seu ponto culminante nos momentos de auge nos meios de comunicação e, logo, se escassearam. Estas mesmas reações se repetiram nas "crises" de 2000-2001. Em qualquer caso, parece também que um bom número de consumidores modificou profundamente suas atitudes. A amplitude e a virulência das reações estão, indiscutivelmente, ligadas ao cúmulo de elementos da situação: 1) o desconhecimento do prion, reconhecido pelos cientistas, é fonte de ansiedade, como todos os fenômenos desconhecidos e a ideia de que este "agente" pode penetrar no cérebro e fazer perder as suas capacidades não pode ser mais que enlouquecedora, sobretudo levando em consideração que os efeitos não são imediatos e sim a prazo desconhecido; 2) a transgressão das leis da natureza (transformar um herbívoro em carnívoro) se integra dificilmente na cultura da maioria de indivíduos e pode fazer perigar a integração de sua carne no universo do comestível (LAMBERT, 1977, p. 243); 3) o lugar central que ainda tem a carne na maioria dos lares populares dos países europeus (CAZES-VALETTE, 1997); e 4) o papel que é jogado pelos meios de comunicação de massas contribuiu para aumentar os temores mais do que para diminuí-los ${ }^{2}$. Os meios de comunicação, diz Savey (1997) a respeito, são, em geral, incapazes de tratar os problemas complexos e de mobilizar o conhecimento no ritmo em que as notícias são difundidas. Suas informações não podem descrever corretamente as realidades evolutivas e complexas. Não podem, portanto, evitar ou participar em manipulações como as que tiveram lugar durante a crise das "vacas loucas". Ao mesmo tempo em que são informadores do público e atores enquanto informadores, os meios de comunicação podem contribuir para pôr em perspectiva no tempo e no espaço os acontecimentos que sofremos como consumidores de informações.

2 En 1996, a revista Lancet publicou um artigo, de origem francesa, afirmando que os macacos alimentados com farinha de carne apresentavam uma encefalopatia parecida com a doença de Creutzfeldt-Jacob. Este artigo teve uma enorme repercussão na imprensa. Ao mesmo tempo, na Grã Bretanha, Mme. Baker, especialista nestas doenças, dispõe de uma colônia de pequenos primatas alimentada com farinha de carne há quinze anos e declara não ter encontrado nenhum caso em uma centena de indivíduos. Depois de publicado, uma discussão em Lancet colocava em dúvida as conclusões do primeiro artigo francês, porém não teve eco em nenhum meio de comunicação. 
Definitivamente, como destacou Rèmond-Gouilloud (1997, p. 127128), a crise da "vaca louca", ao revelar a "coisificação" do mundo vivente, suscita uma repulsão frente à racionalidade produtivista aplicada ao mundo animal. A relação íntima que une os seres vivos, desde agora patente, indiscutível, convida a aprofundar sobre a relação entre o homem e seu contexto natural e, no plano jurídico ao menos, a revisar o tratamento; o meio, rito de passagem para esta ordem referendada, cumpriu bem seu papel, na vanguarda dos interrogantes do nosso tempo. Contudo, na hora de traduzir esta constatação em ação, isto é, em termos de direitos e deveres, a vida conceitual surpreende. Enquanto que em outros lugares o antigo, os animais sagrados e o divinizado expressavam cada um, um valor utilitário ou simbólico, a racionalidade "judeu-cristã", apagando este aparelhamento sutil, relegou todos à categoria informe das coisas. De repente, parece incongruente que o tigre mais lindo do mundo e o cachorro mais fiel não sejam mais que uma pedra; a única diferenciação parece se sustentar na "frescura" e nos caprichos humanos e oscilando entre a categoria do prejudicial e a das espécies protegidas. O pensamento legislativo se reforma e reconhece o animal como um ser sensível e com direitos. Assim, para Rèmond-Gouilloud, a monstruosidade não é que a vaca seja louca, mas que seja o homem quem a enlouqueça. $\mathrm{Na}$ Espanha, desde $1^{\circ}$ de outubro de 2004 o Código Penal configura como delito o "maltrato de animais domésticos".

Algumas reações "nacionais" e/ou "nacionalistas" à crise das "vacas loucas" podem nos proporcionar alguns caminhos para valorizar a dimensão cultural existente no consumo de carne na atualidade. Cazes-Valette (1997, p. 210-211), evocando as noções de etnocentrismo e de xenofobia de Lévi-Strauss - e mais concretamente a atitude de repúdio com relação às formas culturais que resultam distanciadas daquelas com as quais nos outros nos identificamos e que se inscrevem nas fronteiras da tribo ou do grupo linguístico -, afirma que pode compreender-se que alguns franceses, desprezando toda distância científica, se contentaram com a menção VF (Viande Française) para se tranquilizar frente à ameaça das "vacas loucas". O inimigo está no estrangeiro (neste caso, Inglaterra).

O que ocorre é que a industrialização, como já foi dito, provocou a perda de "referências", porém os consumidores continuam tendo necessidade delas. Na falta de outras referências relativas ao lugar de produção, às matérias-primas, às técnicas de manipulação ou a compreensão precisa 
das informações que os produtores fornecem com relação a tudo isso, a "marca" aparece como um novo e possível "sinal de identidade", que pretende conferir segurança, confiança. Contudo, no caso das carnes, na falta de "marcas" produtoras, proliferam as "Denominações de Origem", as "Indicações Geográficas Protegidas" ou bem as "marcas" dos grandes estabelecimentos, as das Grandes Cadeias de Distribuição. Assim mesmo, marcas coletivas do tipo "Etiqueta Vermelha de Qualidade", "Agricultura Biológica" ou "Agricultura Ecológica" permitem sair da massa de indiferença das carnes anônimas aos produtos sobre os quais uma entidade se compromete com a transparência sobre determinados critérios, dos quais um dos mais importantes é a origem ou a identidade dos produtos. Tudo isso poderia explicar, de acordo com Cazes-Valette (1997, p. 222-223), por que estes tipos de marcas ou etiquetas diminuíram sua venda de carnes por conta da "crise das vacas loucas" mais do que as que não tinham a "marca"; pois, além do seu papel jurídico de proteção, a marca ou o produto os destacam, os identificam e constitui um compromisso por parte de "seu autor" e garante uma constância, uma melhora da oferta que é promovida como diferenciada e diferenciável daquelas ofertadas pelos concorrentes. Uma marca reconhecida inspira mais confiança.

\section{Os "novos alimentos" e os "medos alimentares": o caso do peixe}

Já dissemos que os alimentos mudaram muito ao longo dos últimos 40 anos. Por definição, as inovações alimentares se caracterizam por diferenças mais ou menos importantes em relação aos produtos conhecidos. Portanto, os novos produtos podem suscitar certas dúvidas ou problemas e resultam ser menos toleráveis quanto maior é a diferença ou distância em relação aos produtos já assimilados. A inovação acaba sendo mais bem aceita quanto menor for a diferença em relação ao sistema de representações e a cultura preexistente. Até que ponto os alimentos que hoje consumimos são os mesmos que antigamente? O caso do "peixe" constitui outro exemplo. O peixe já não tem o significado sociocultural preciso que tinha antigamente. Com 
relação ao peixe, ao longo dos últimos anos apareceram diversas inovações com diferentes tipos de significação, assim como de aceitação ou desprezo: congelados, análogos, funcionais... Assim, hoje, os produtos do mar estão, da mesma maneira que muitas outras categorias de alimentos, tecidos por certa ambivalência. São alimentos naturais ou industriais? Até certo ponto, nada pareceria mais natural que um peixe fresco recém-pescado. Contudo, é sabido que tanto os rios como os lagos devem ser repovoados, que a pesca em alto mar cada vez se parece mais com uma indústria e menos com uma atividade artesanal, que a aquicultura não para de se desenvolver e que o peixe selvagem cada vez é mais escasso. Por outro lado, a contaminação marinha e dos rios e o risco de infecções bacterianas e virais colocam em cheque a pureza dos produtos do mar.

Geralmente, os novos produtos "de peixe" têm uma boa aceitação por parte dos consumidores, inclusive superior ao de outras inovações alimentares. Além do preço, comparavelmente mais vantajoso, cabe destacar suas diferentes possibilidades e graus de conveniência e sem que suas características nutricionais se vejam negativamente afetadas, principalmente em comparação com, por exemplo, os produtos da carne ou a "confeitaria" industrial em torno dos quais se teceu certa atmosfera de desconfiança. Efetivamente, ainda que existam algumas diferenças com relação ao sabor, cheiro e, principalmente, textura entre o peixe fresco e o congelado, este último acaba sendo conveniente porque é mais barato, sua compra não tem que ser diária, se cozinha mais rapidamente e, inclusive, já pode vir sem espinhas. Essas vantagens do peixe congelado facilitam para um uso mais cotidiano. Neste sentido, desde o ponto de vista dos consumos ordinários, seria possível dizer que o peixe congelado substituiu o peixe conservado em sal. Por outro lado, desde o ponto de vista nutricional, razão cada vez mais importante, são escassas as diferenças entre peixe fresco e congelado.

Os produtos surimi podem se tornar atraentes para o consumidor atual, já que, imitando outros de maior prestígio e de maior custo, se apresentam como uma solução de cozinha rápida e fácil. No mundo, são mais de uma centena os produtos deste tipo usados diariamente e continuam sendo anunciadas novidades como o surimi de anchova ou de perceve. Ainda que os produtos à base de surimi pareçam ser menos "naturais" que os peixes, sua qualidade nutritiva é muito satisfatória. Para cada 100 gramas, contém: 10,9 gramas de proteínas; de 0,2 a 0,4 de lipídios; de 3 a 6 de glucídios e 
de 1 a 1,4 de sal. Trata-se, pois, de um alimento rico em proteínas, baixo em calorias ( $65 \mathrm{kcal}$ x 100 gramas), barato e que permite aproveitar peixes que ninguém ia querer na sua forma natural. Além do que, quase nunca se consomem como prato principal e sim como aperitivo ou complemento de outros pratos; logo, suas possíveis deficiências em algum nutriente podem ser compensadas por conta da facilidade do acréscimo de outros ingredientes.

Já foi dito que a nossa modernidade alimentar se caracteriza pela proliferação dos medos alimentares e uma arraigada sensação de insegurança em relação aos alimentos que consumimos. Até agora, chamou-se a atenção, fundamentalmente, sobre o pesticida no legume, o hormônio na carne, o colesterol na artéria, a salmonela no frango ou no ovo, o prion na vaca, o excesso de lipídio, de sal, de açúcar etc. E tudo isso com a temida consequência da obesidade, do câncer de todos os tipos, da prisão de ventre, da gastroenterite, de doenças cardiovasculares etc. À vista da relação anterior, seria possível pensar que os medos atuais beneficiaram mais do que prejudicaram o consumo de peixe. Até certo ponto, é certo que as crises alimentares com relação aos produtos da carne ("vacas loucas", "dioxinas", "peste porcina" etc.) puderam dar lugar a certo crescimento, ainda que circunstancial e pouco perceptível nas séries estatísticas, na demanda de peixe, tanto no que se refere ao volume de vendas como nos preços.

Definitivamente, os peixes, em comparação com outros alimentos, saíram-se relativamente bem da relação desses medos. Porém não estão isentos. Além da sua fragilidade característica e da histamina que liberam com tanta facilidade, os derivados dos modelos intensivos da exploração dos recursos e da degradação ambiental começam a afetar os produtos do mar. O mercúrio é o mais comentado, até o ponto de que alguns já se perguntaram se deveriam limitar o consumo de peixe como consequência das doses de mercúrio contidas no mesmo. O medo, de momento, ao menos, parece não estar justificado na opinião dos especialistas; é certo que em doses altas provoca danos neurológicos, porém, os peixes consumidos têm baixas quantidades de mercúrio e sem efeitos nocivos demonstrados.

Até o momento, os peixes foram associados com os modelos intensivos de produção alimentar e sua imagem social negativa. Os produtos do mar continuam sendo percebidos majoritariamente como "produtos naturais". Contudo, esses problemas de imagem associados com a produção intensiva estão começando a aparecer à medida que algumas variedades 
de peixe são mais cultivadas que pescadas e que a aquicultura tem uma importância crescente. Os meios de comunicação já informam da utilização de aditivos como, por exemplo, a caseína no salmão embalado para melhorar a sua textura e a sua estrutura. Assim mesmo, o fato de que as "granjas marinhas" tenham empregado rações com farinhas à base de carne, da mesma maneira que se alimentam os patos e os coelhos de outras granjas, pode não beneficiar a imagem desses peixes, até agora muito bem aceitos pelos consumidores, porém poderia ver-se afetada pela mesma imagem negativa associada aos engordes acelerados de outros animais.

Outras particularidades, relativas tanto à percepção dos produtos de pesca como às inquietudes de determinados movimentos sociais em auge, como os ecologistas, podem afetar em algum grau a aceitação dos "peixes de cultivo" e do peixe em geral à medida que este se associa definitivamente com a negativa percebida pela "industrialização da alimentação", pelo desconhecimento da origem e características dos alimentos consumidos.

Por tudo isso, não seria de se estranhar que, assim como ocorreu em 1996 com o "novilho galego", ao qual se expediu um carnê de identidade para garantir sua cordura, hoje se deve expedir, também, ao peixe para conhecer sua procedência e sua identidade, para o conhecimento do consumidor:

Para saber o que você pesca! Agora, o peixe tem RG. Consulte a nova etiqueta informativa que você encontrará na sua peixaria. Com toda a informação que você necessita para garantir a melhor qualidade do peixe: a origem, o frescor, a forma de obtenção e a apresentação. Assim, você sempre saberá o que pescou [M.A.P.A. Secretaria Geral de Pesca Marítima (anunciado no jornal El País Semanal, 2002)].

\section{O paradoxo da segurança alimentar}

O aumento da expectativa de vida, a redução das influências religiosas, o maior desenvolvimento dos conhecimentos científicos e o aumento na crença de que "tudo se pode conseguir" dá lugar ao desenvolvimento do 
mito do "risco zero". O aumento dos conhecimentos científicos, a melhora nas técnicas de controle e o próprio aumento dos controles permitem uma maior detecção dos constituintes patógenos. Tudo isso dá lugar ao que se poderia chamar de paradoxo da segurança alimentar: de um lado, o sistema de produção alimentar se preocupa cada vez mais, consegue uma maior segurança e, consequentemente, os riscos são cada vez mais raros; porém, por outro lado, a mesma escassez de riscos e sua utilização como pretexto protecionista comporta um forte aumento da imediatização e o aumento da percepção dos riscos por parte da população, sobretudo quando os efeitos das aplicações das novas tecnologias resultam pouco conhecidos ou de todo desconhecidos (hormônios, "vacas loucas", organismos geneticamente modificados etc.).

A percepção sobre os riscos alimentares se integra e explica em um contexto cultural caracterizado por determinados valores sociais e morais, por determinadas concepções sobre o corpo e a imagem corporal, por uma determinada visão de doença e de saúde. Ainda que se admita que o risco zero não exista, a capacidade ou a disposição para assumir riscos em alimentação é muito inferior que em qualquer outro campo do consumo. Ademais, os consumidores distinguem diferentes tipos de risco: os acidentais e os evitáveis e os provocados como consequência de práticas descuidadas, ineficazes ou abertamente fraudulentas. Não se trata, pois, de uma incapacidade generalizada por assumir o risco, senão uma reticência ao assumir riscos desnecessários e que não leva a nenhuma vantagem. Pode-se estar disposto a assumir um risco, mais ou menos incerto, se algumas vantagens são percebidas pela sua utilização. Um produto alimentar suspeito sempre é substituível por outro produto alimentar. Isto é, a evitabilidade do risco e a possibilidade de substituição são dois elementos-chave na hora de assumir riscos.

A industrialização do setor agroalimentar foi acompanhada por uma ruptura fundamental das relações que os seres humanos haviam mantido fisicamente com seu meio e com o fato de que numerosas tarefas, que até então eram realizadas pelas responsáveis domésticas nas suas respectivas cozinhas, hoje acontecem em uma fábrica (GOODY, 1982; CAPATTI, 1989; CONTRERAS, 1999; WARDLE, 1987). A “industrialização", percebida em grande medida como uma "artificialização" da alimentação deu lugar a uma ideia cada vez mais persistente e, também, mais certa, de que cada 
vez sabemos menos sobre o que comemos. Esta ideia ou percepção resulta facilmente aceitável se temos em conta que os alimentos são cada vez mais "processados", mais transformados, de tal modo que a cadeia alimentar é cada vez mais complexa e, assim mesmo, mais distante ou distanciada do cidadão. Porém, também, e em um sentido muito diferente, a sucessão e a relativa frequencia de "crises alimentares" contribuem para "colocar em evidência" aspectos não conhecidos, não imaginados e "não aceitáveis" em relação à "manipulação" dos alimentos; pois, pode tratar-se de aplicações tecnológicas cuja existência e alcance se desconheciam previamente, como, por exemplo, as vacas comendo farinhas de carne elaboradas com os dejetos dos próprios animais ou com restos de ovelhas doentes.

Efetivamente, nos últimos anos, a indústria alimentar colocou em circulação uma série de "novos produtos" cujas especiais ou novas características consistem, fundamentalmente, em alterar sua composição e/ou sua "filiação". A pecuária e a avicultura industrial, por exemplo, deram lugar a "raças artificiais", aves "monstruosas" que produzem grandes quantidades de carne, para conseguir uma produção em massa. As "alterações" podem consistir na eliminação de algum de seus componentes mais característicos, como, por exemplo, a "gordura", ou na eliminação da carne por completo, mantendo, assim, o nome do produto, o aspecto, a cor e alguma referência ao seu sabor e à sua textura. Pode-se dizer que a agricultura e a pecuária se afastam, cada vez mais, da "natureza" para aproximar-se cada vez mais do laboratório e da indústria. E, também, os "peixes", ainda que a palavra "peixe" tenha que derivar-se somente de "peixe" e não de "pesca". Efetivamente, espécies como a truta, o salmão, a luvina e o robalo já podem não ser "pescadas" e sim “cultivadas". A estas espécies se acrescentarão outras como, por exemplo, o atum, pois pesquisadores japoneses já conseguiram reproduzir $\mathrm{o}$ atum em cativeiro mediante técnicas de laboratório. Esses atuns pesam um pouco menos que os "normais", que a partir de agora se chamarão "selvagens", porém, pelo contrário, são mais ricos em gorduras, o que aumenta seu valor no mercado internacional.

Desta maneira, o desenvolvimento recente da tecnologia ou da indústria alimentar perturbaram a dupla função identificadora do culinário, isto é, da identificação do alimento e a construção ou a sanção da identidade do sujeito (FISCHLER, 1985, p. 188). Entre a tecnologia, de um lado, e o marketing e a publicidade, de outro, as referências culturais de alimenta- 
ção foram destruídas, isto é, as possibilidades de identificar os alimentos se perderam. $\mathrm{O}$ alimento teria se convertido em um objeto sem história conhecida e o consumidor moderno não saberia o que é que realmente está comendo (FISCHLER, 1979, p. 202), pois a indústria parece proporcionar (em Lambert, 1997) um fluxo de "alimentos sem memória". Portanto, antes do consumidor (conceito relativamente novo) não se tinha consciência do que realmente comemos: embutidos sem carne de porco, sucedâneos de enguia, caviar etc., etc.; animais e plantas modificados geneticamente, produtos enriquecidos, lights, sem, des, com, inteligentes, energéticos, vacas que não comem pasto, peixe que come ração de carne, novos conceitos, tais como colesterol bom e mau colesterol, gorduras polissaturadas, monoinsaturadas, ômega 3, cálcio, polifenóis, antioxidantes, flavonoides, bífidos, lactobacilos etc.

Provavelmente, antes, a distância entre o conhecimento científico (aceleradíssimo e modificante) sobre os alimentos (em particular) e sobre a alimentação (as dietas) e o conhecimento popular havia sido tão grande na linguagem, no alcance e nas implicações dessa distância e nos novos modos como se atribuem as responsabilidades: "falta educação nutricional", "falta informação", "falta informação adequada", "faltam medidas preventivas", "procura desmesurada do benefício" etc. Por exemplo, a conclusão dos autores de um documento ${ }^{3}$ a respeito do conhecimento alimentar da população é que, "apesar da importância que lhe é dada, a população apresenta um conhecimento bastante medíocre: conhecem de maneira muito limitada os alimentos que contém certas matérias básicas, e os benefícios associados a alguns alimentos importantes da dieta mediterrânea". A opinião da maioria dos especialistas (tecnólogos, nutricionistas e industriais, principalmente) coincide com as deste estudo. Efetivamente, os especialistas e os industriais insistem enfaticamente na falta de formação nutricional dos consumidores e na importância que a formação nutricional tem para o desenvolvimento de uma melhor alimentação e uma maior aceitação dos novos produtos e, concretamente, dos alimentos funcionais.

A insegurança alimentar está instaurada nas representações sociais dos comensais contemporâneos (APFELBAUM, 1998; PERETTI-WATEL,

3 ¿A dónde va la alimentación? Estudio de las actitudes hacia la alimentación. In: FORO INTERNACIONAL DE LA ALIMENTACIÓN, 4., Barcelona, 2002, p. 205. 
2000, 2001), ainda que as percepções do risco variem substancialmente dependendo do contexto em que é gerado. Normalmente, as sucessivas crises nos permitem trazer à luz a dificuldade real em estabelecer os limites entre riscos reais e riscos subjetivos. As pessoas não deixam de dirigir apesar de que a cada ano milhares de europeus morrem nas estradas, vítimas de um acidente de carro; porém, questionam a sua comida porque associam riscos negativos aos alimentos. A contradição do sistema alimentar moderno entre a abundância e o risco tentou explicar estas diferentes posturas, algumas vezes argumentando que negar-se a comida é um mecanismo de racionalidade humana, uma resposta ante a abundância, e outras dizendo que é uma expressão da insegurança produzida pelos processos anômicos que caracterizam nosso entorno cultural. Seja pela reação ou pela crise, o certo é que estamos diante do que podemos qualificar de um novo sistema alimentar: o modelo de comportamento atual mudou suas formas e seus conteúdos com respeito a modelos alimentares anteriores, ainda que persistam numerosos elementos imutáveis.

A recorrência das chamadas crises, alarmes e escândalos alimentares contribuíram para questionar de forma crescente os sistemas de prevenção de risco e, por conta dessas crises, motivou uma recusa temporal de diferentes tipos de produtos alimentares. Tudo isso, por sua vez, deu lugar a um amplo debate sobre as características da segurança alimentar e as reações dos consumidores.

Nos últimos anos, a confiança dos consumidores na segurança dos alimentos e na eficácia dos controles se colocou sob suspeita. Os recentes escândalos alimentares tiveram um impacto direto na competitividade da indústria. Estudos realizados indicam que os escândalos podem ter, em longo prazo, um efeito significativo na demanda, assim como a credibilidade dos mecanismos de regulamentação das companhias agroalimentares, em particular quando durante os escândalos alimentares não se dão explicações com fundamentação científica ou quando a credibilidade da instituição se coloca em suspeita porque se considera que esta somente protege os seus próprios interesses. Todos esses fatores não somente provocam desconfiança sobre alguns alimentos, como sobre a totalidade da cadeia alimentar, cientistas e políticos incluídos. Assim, a pergunta recorrente dos consumidores é: $O$ que podemos comer sem medo? 
O "medo alimentar" não deixa de ser paradoxal porque, ao longo da história dos hoje chamados países desenvolvidos, em nenhum outro momento os seres humanos se sentiram tão bem e durante tanto tempo como atualmente. As melhorias decisivas aportadas pela higiene e pela medicina permitem à maioria da população esperar a chegada da terceira idade com uma boa saúde. A partir dos 65 anos, a expectativa de vida é de uns 15 anos para os homens e de 20 para as mulheres. Seria possível pensar que já se alcançou um objetivo vital da espécie e que os progressos futuros no terreno da higiene e da nutrição somente terão efeitos marginais para a coletividade e sua saúde. Contudo, o aumento do medo é um fato social inevitável que se apoderou, inclusive, dos espíritos mais rigorosos. Foram encontrados novos bodes expiatórios nas pessoas dos obesos, dos diabéticos ou dos hipercolesterolímicos. A proporção real da população que constitui os grupos de risco alimenta a angústia coletiva. $\mathrm{O}$ discurso do medo é hoje também o discurso do establishment, cujos atores são o poder público, os dietistas e as empresas. Os meios de comunicação de massas, por sua vez, orquestram magnificamente todo um cenário que contribui para difundir o grande medo através de um discurso nutricional que se converteu em ideologia dominante (APFELBAUM, 1989, p. 180-181).

\section{Conclusão}

O reconhecimento fortuito e inesperado do risco e sua concreção em algo tão cotidiano, frequente e inevitável como é a comida, especialmente quando se trata dos alimentos básicos, os mais consumidos e os mais valorizados (carnes, cereais, peixes), se traduziu de diversas maneiras, pois os indivíduos apreendem os riscos de acordo com seus valores e suas crenças (DOUGLAS, 1996). Assim, gera-se uma desconfiança cada vez maior na cadeia alimentar. Em matéria de alimentação, a população não parece querer aceitar riscos desnecessários e considera pouco útil ou pouco vantajosas algumas das aplicações das inovações científicas e tecnológicas no âmbito da comida: alimentar as vacas com farinha de carnes infectadas, aplicações tecnológicas orientadas não tanto na melhoria da qualidade organoléptica dos alimentos ou seu valor de saúde, mas para facilitar sua conservação, transporte, acelerar sua maturação ou crescimento etc. 
Assim mesmo, desenvolve-se um ceticismo generalizado frente à maneira de administrar e resolver politicamente os problemas que dizem respeito ao cidadão mais diretamente, seja em termos de saúde, economia ou meio ambiente.

A desconfiança e o ceticismo social implicam em um questionamento do modelo científico e dos objetivos da ciência, porém, sobretudo do modelo de gestão política. Cada controvérsia alimentar coloca em destaque as mesmas questões: incerteza, ocultação de informação, medidas insuficientes, avaliações científicas contraditórias. Ademais, os consumidores não detectam mudanças significativas nas maneiras de atuar e de dar resposta aos problemas que vão surgindo e nem no modo de informar ou levar em consideração suas opiniões. Para os especialistas, muitas das crises alimentares foram somente "sustos" mais ou menos irrelevantes (casos como: "azeite de bagaço", "vacas loucas", "alimentos transgênicos", "frangos com dioxinas", "hormônios para engorda de gado"...) com relação ao número de pessoas afetadas, pois a probabilidade de contrair alguma doença grave ou, inclusive, de morrer, foi muito baixa. Contudo, para a maior parte da população, esses problemas costumam ter outro significado. Evidenciam determinados aspectos "invisíveis" da cadeia alimentar. Revelam, também, que, apesar de as produções de alimentos estarem jurídica e cientificamente mais controladas do que nunca, existem falhas importantes em diferentes níveis da cadeia. A população é sensível a todo este tipo de experiências, as quais, por sua vez, moldam as representações sociais.

\section{Referências}

ABRAHAMSSON, L. The mother's choice of food for herself and her baby. In: BLIX, G. (Ed.). The Mother-Child Dyad: Dietary aspects. Upsala: Alkquist and Wiksells, 1979.

APFELBAUM, M. La recherche face aux peurs du siècle. Nourritures, Paris: Autrement, n. 108, p. 180-184, 1989.

. La diète prudente est-elle bien raisonnable? Manger magique. Aliments

sorciers, croyances comestibles, Paris: Autrement, n. 149, p. 179-183, 1994. 
APFELBAUM, M. (Dir.). Risques et peurs alimentaires. Paris: Odile Jacob, 1998. ARIÈS, P. La fin des mangeurs. Les metamorphoses de la table à l'âge de la modernisations alimentaire. Paris: Desclée de Brouwer, 1997.

ATKINSON, P. Eating virtue. In: MURCOTT, A. (Ed.). The sociology of food and eating: Essays on the sociological significance of food. Hants: Gower Publishing, 1983, p. 9-17.

CACERES, J.; ESPEITX, E. Riesgo alimentario y consumo: percepción social de la seguridad alimentaria. In: GRACIA, M. (Ed.): Somos lo que comemos. Estudios de alimentación y cultura en España. Barcelona: Ariel, 2002, p. 317-348.

CAMPION-VINCENT, V. La véritable histoire de l'os de rat. In: Manger magique. Aliments sorciers, croyances comestibles, Paris: Autrement, n. 149, p. 84-92, 1994.

CAPATTI, A. Le goût du nouveau. Origines de la modernité alimentaire. Paris: Albin Michel, 1989.

CAZES-VALETTE, G. La vache folle. Cultures, nourriture, Paris: Maison des Cultures du Monde, p. 205-233, 1997.

CONTRERAS, J. Cambios sociales y cambios en los comportamientos alimentarios en la España de la segunda mitad del siglo XX. Anuario de Psicología, v. 30, n. 2, p. 25-42, 1999.

; GRACIA, M. Alimentación y cultura. Perspectivas antropológicas. Barcelona: Ariel, 2005.

C.R.E.D.O.C. Manger est perçu comme présentant davantge de risques. Consommation et modes de vie, n. 148, 2002.

DOUGLAS, M. La aceptabilidad del riesgo según las ciencias sociales. Barcelona: Paidós, 1996.

FISCHLER, C. Gastro-nomie et gastro-anomie: sagesse du corps et crise bioculturelle de l'alimentation moderne. Communications, n. 31, p. 189-210, 1979.

. Alimentation, cuisine et dientité: l'identification des aliments et l'identité du mangeur. Recherches et travaux de l'Institut d'Ethnologie, n. 6, p. 171-192, 1985.

. Gastro-nomía y gastro-anomía: sabiduría del cuerpo y crisis biocultural de la alimentacion contemporánea. In: CONTRERAS, J. (Comp.). Alimentación y cultura: necesidades gustos y costumbres, 1995, p. 357-380.

GOODY, J. Cuisines, cuisine et classes. Paris: Centre George Pompidou (Edición española: Cocina, cuisine y clase. Barcelona: Edit. Gedisa), 1984.

GRACIA, M. Paradojas de la modernidad alimentaria. Barcelona: Editorial Icaria, 1996. 
(Ed.) Somos lo que comemos. Estudios de alimentación y cultura en España. Barcelona: Ariel, 2002.

GRUHIER, F. Quand les ingénieurs font la cuisine. Autrement, n. 108, p. 120-124, 1989.

GRUNERT, K. G.; LARSEN, H.; MADSEN, T. K.; BAADSGAARD, A. Market Orientation in Food and Agriculture. Boston: Kluwer, 1996.

JEGOU, F. Nourritures artificielles. Le rôle du design dans l'avenir de l'industrie alimentaire. In: Programme Alimentation Demain. Ministério de Agricultura, DCAL-Dâlt. Paris, 1991.

LAMBERT, J. L. Les mangeurs entre traditions et nouveautés: quelques specificités du 'marketing alimentaire. In: GIACHETTI, I. (Ed.): Identités des manguers. Images des aliments. París: Polytechnia, 1996.

. Les mangeurs face aux nouvelles technologies alimentaires; conséquences

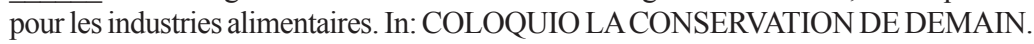
Actas... Burdeos, 1997.

. Quelques déterminants socioculturels des consommations de viandes en Europe. La "vache folle" va-t-elle renforcer la tedance à la sarcophagie et au néovégétarisme? Reveue du Droit Rural, n. 252, p.240-243, 1997 a.

MAHO, J.; PINSON, P. Cantines, comment s'en débarrasser? Autrement, n. 108, p. 200-204, 1989.

MANDERSON, L. Suministro de alimentos y cambio social en el sureste asiático y en el Pacífico Sur. In: Carencia alimentaria. Una perspectiva antropológica. Barcelona: Ediciones del Serbal, 1988, p. 178-202.

PERETTI-WETEL, P. Sociologie du risque. Paris: Armand Colin, 2000.

. La société du risque. Paris: La Decouverte, 2001.

POULSEN, C. S.; JUHL, H. J.; KRISTENSEN, K.; BECH, A. C.; ENGELUND, E. Quality guidance and quality formation. Food Quality and Preference, n. 7, p. 127-135, 1996.

PYNSON, P. Mangeurs fin de siècle. Autrement, n. 108, p.186-192, 1998.

RÈMOND-GOUILLOUD, M. Entre "bêtises" et précaution. Esprit, n. 11, p. 118$128,1997$.

SAVEY, M. Les leçons de la "vache folle". Esprit, n. 11, p. 101-117, 1997.

STEEMKAMP, J. Conceptual model of the quality perception process. Journal of Bussiness Research, n. 21, p.309-333, 1990. 
SYLVANDER, B.; MELET, I. La qualité spécifique en agro-alimentaire: marchés, institutions et auteurs. INRA-Toulouse, Serie P, n. 94-01, 1994.

VASSEUR, P. La révolution alimentaire. Que mangerons-nous demain? Paris: Hachette, 1997.

WARDLE, C. Changing food habits in the United Kingdom. Londres: Earth Resources Research Ltd., 1977.

Recebido em agosto de 2010.

Aprovado em agosto de 2010. 